\title{
Mental Health and Political Representation: A Roadmap
}

\author{
Luca Bernardi * \\ Department of Politics, University of Liverpool, Liverpool, United Kingdom
}

Research on health and political behavior has identified a significant mental healthparticipation gap that is likely to have important consequences for political equality. Yet such consequences remain by and large unexplored. Inspired by 60 years of empirical research on public opinion, media and policy, this article proposes a roadmap for research on the political representation of mental health. It advances a number of research questions around 1) opinion formation and issue emergence and evolution, 2) multiple and complementary societal signals that can influence policy makers' issue attention and policy change, and 3) different conceptions of representation and their consequences for public attitudes and political participation. The article also provides a preliminary attempt at addressing whether mental health spending incorporates signals from public preferences for spending on mental health services or policy problems. Making use of time-series data on spending on mental health services by local authorities in England between 1994 and 2013, the analysis finds no statistical association between spending and policy problems and reveals a negative relationship between spending and public preferences, suggesting

OPEN ACCESS

Edited by: Elisabeth Gidengil, McGill University, Canada

Reviewed by:

Peter Söderlund,

Åbo Akademi University, Finland Hannu Lahtinen,

University of Helsinki, Finland

*Correspondence: Luca Bernardi luca.bernardi@liverpool.ac.uk

Specialty section: This article was submitted to Elections and Representation,

a section of the journal Frontiers in Political Science

Received: 26 July 2020 Accepted: 23 December 2020 Published: 29 January 2021

Citation: Bernardi L (2021) Mental Health and Political Representation: A Roadmap. Front. Polit. Sci. 2:587588. doi: 10.3389/fpos.2020.587588 that if spending is reacting at all to preferences, it misrepresents them. This article invites scholars to collect more data and produce more research that will guide interventions to help overcome stigma and participation challenges that undermine political equality as one of the key principles of democracy.

Keywords: political representation, policy, public opinion, mental health, stigma

\section{INTRODUCTION}

Research on mental health in political behavior is in its infancy but growing fast. Most scholarly attention has been focusing on the negative effect of mental health deterioration on political participation, especially voting (Ojeda 2015; Burden et al., 2017; Couture and Breux 2017; Sund et al., 2017; Ojeda and Pacheco 2019; Ojeda and Slaughter 2019; Landwehr and Ojeda 2020). Only more recently have scholars started paying attention to the relationship between mental health and political attitudes. Yet this work exclusively examines the link between depression symptoms and diagnosis and political predispositions (Bernardi, 2020), attitudes to change in highly uncertain situations (Bernardi and Johns 2020), political efficacy (Bernardi et al., N.d.), political interest (Ojeda et al., N.d.), and evaluations of political objects (Bernardi and Johns N.d.).

Although a lot more needs to be done, the message from previous research is clear: there is a mental health-participation gap and this gap is worrisome because it is likely to lead to inequality in policy representation and to carry serious implications for mental illness stigma. Yet no extant research investigates policy representation on mental health (but see Pacheco and Ojeda (2019) on inequality in policy congruence on health in the United States), a gap that is even timelier to fill in 
response to Lancet Psychiatry's recent call for action on multidisciplinary research on mental health (Holmes et al., 2020).

Mental health is a low-salience issue. As such, it has never made it to the list of the 'most important problems/issues', although its salience is growing in the face of COVID-19 (e.g., UN News 2020). Usually, public opinion has in mind the public health system when thinking of health, and so mental health might be particularly important only for specific groups or "issue publics" (Krosnick 1990) rather than for the general public. Indeed, this idea of mental health as "policy for the few" is echoed in work on group identification as an important determinant of mental health policy preference formation (McSween, 2002). Although there has recently been an increase in positive articles on mental illness, for example in the United Kingdom press (Thornicroft et al., 2013), and positive news reports can help reduce stigmatizing attitudes (Ross et al., 2019), the issue rarely makes front page headlines. Moreover, the issue is often framed negatively, with people with mental illness being portrayed as unpredictable, unsociable, dangerous or even violent, thereby perpetuating misconception, misinformation and stigma (e.g., Stout et al., 2004; Klin and Lemish 2008).

On the other hand, mental illness is an increasingly problematic issue in Europe (Gustavsson et al., 2011; Wittchen et al., 2011) and elsewhere. Any given year, one in three Europeans experiences at least one diagnosable mental health problem and mental disorders represent the greatest health burdens to Europe (Wykes et al., 2015). A recent estimate of yearly costs for mental disorders in Europe is $€ 461$ billion (Gustavsson et al., 2011)-excluding any costs of dementia and other neurological disorders. This figure is largely due to the indirect costs to social welfare, employment, wellbeing and economic output, of which mental illness stigma is an important cause. Stigma affects both public opinion and people with mental illness, but it is also embedded in the media and political institutions (Corrigan 2004; Corrigan et al., 2004; Thornicroft et al., 2007). Reducing stigma has been set as a key priority for mental health research in Europe (Wykes et al., 2015) and anti-stigma programmes have been developed around the world-led first by the World Psychiatric Association and more recently by the World Health Organization and individual countries (starting with Australia, New Zealand, Britain, and the United States) that have recognized the call for change and provided significant resources to fight stigma (Corrigan et al., 2011). Last but not least, resources for mental health are scarce, unequal and inefficient (Saxena et al., 2007). Thus, if mental health is not conventionally an important issue in electoral terms, it is a problematic one and its salience is increasing rapidly in the light of government responses to the COVID-19 pandemic.

This article advances a research agenda on the political representation of mental health inspired by what we know from 60 years of empirical research on public opinion, media and public policy. This is the main contribution of this article. What follows is not meant to be an exhaustive review of this enormous body of research. This has already been done and remarkably well elsewhere (e.g., Burstein 2010; Wlezien 2020). Rather, I have selected some of the take-homes from this vast and diversified literature to formulate key questions to guide the generation of hypotheses that can enhance our knowledge and understanding of mental health as a policy issue, opinion formation around it, and how representation comes about.

In the second part of the article, I start addressing one of the proposed research questions by focusing on what kind of opinion signals-either public preferences or the emergence mental healthrelated policy problems-may influence policy change on mental health using time-series data on spending on mental health services by local authorities in England (1994-2013). On the one hand, the data show no evidence that change in spending is associated with change in mental health-related policy problems. On the other hand, the data show evidence that change in spending is negatively associated with change in preferences for spending on mental health services. This implies that, if spending in England is responding at all to opinion preferences, it misrepresents them.

\section{WHAT ARE THE KEY QUESTIONS?}

Empirical research on mental health policy has long been off the radar of political scientists, especially those interested in political behavior. Not surprisingly, there is an enormous amount of work on mental health in psychiatry and epidemiology, but mental health scholars have of course been interested in other aspects than public opinion, including the socio-economic burden of mental health issues (e.g., Lecrubier, 2001; Gustavsson et al., 2011; Wittchen et al., 2011; Wykes et al., 2015), the effects of mental health advocacy on social exclusion and stigma (e.g., Corrigan et al., 2011; Evans-Lacko et al., 2014), mental health policy making (e.g., Goodwin 1997; Knapp et al., 2007), the importance of structural stigma in policy (e.g., Corrigan et al., 2004; Link and Hatzenbuehler 2016), and interdependence between local authority mental health expenditure and the expenditure decisions of neighboring authorities (e.g., Moscone and Knapp 2005; Moscone et al., 2007).

Mental illness stigma research is well aware of many of the issues briefly discussed below in this section. It is not the first time that political science lags behind. For instance, the neuroscientific and biological foundations of political behavior were initially examined by neuroscientists, physiologists and geneticists rather than political scientists (Hatemi and McDermott 2011). Yet, political science should make an effort to bridge this disciplinary divide and take responsibility by providing answers that link public opinion, media and policy on mental health. Here, I present three major areas of investigation on the political representation of mental health. The discussion is inspired by research on public opinion, media and policy broadly conceived. Using this literature as a guide, I formulate some important questions which could help to motivate future research.

\section{How Does the Mental Health Issue Emerge and Opinion Formation Evolve?}

Is mental health a specific or a crosscutting issue? Is mental health a politicized issue at all? To what extent is it a valence issue or a 
positional issue? ${ }^{\mathrm{a}}$ What type of issue is it? How is it framed and primed and what are the implications for public opinion? ${ }^{\mathrm{b}}$ Do people with mental health problems have different policy preferences and priorities? Do they consider themselves to be a coherent group? Do mental health policy preferences follow a specific or a global trend? All these different questions, which I put under the same umbrella, have to do with issue emergence and evolution, and with opinion formation on the issue, but also with the interconnection between the media, the public and the policy makers (e.g., Iyengar and Kinder 1987; Stimson 1991; Page and Shapiro 1992; Carmines and Stimson 1993; Iyengar and Reeves 1997; Erikson et al., 2002; Kellstedt 2003; Stimson 2004; Chong and Druckman 2007a, Chong and Druckman 2010; Baumgartner et al., 2008; Baumgartner and Jones 2010; Soroka and Wlezien 2010; Gilens 2012; Boydstun 2013).

I cannot discuss in length each of these questions but here I will focus on some aspects that are particularly relevant, starting with group consciousness (e.g., Yzerbyt et al., 2004). Other groups in society like women, gays or people of color have developed strong identities and group consciousness over the past decades. Whereas issues relating to women, homosexuality and race have been around much longer, the mental health issue is relatively new. Although the "mentally ill" (Corrigan et al., 2004) are labeled as such by others-and (public and self-) stigma clearly plays a role-we do not know to what extent they feel that they are a group when participating in politics and expressing their concerns and demands for representation. Also, unlike women, gays or people of color, whose biological or dispositional "status" is generally permanent, this is often not the case for people with mental illness. While some disorders are long-standing (e.g., schizophrenia) or chronic (e.g., depression or anxiety), other people experience episodes of mental illness only sporadically.

Of course, opinion formation and group consciousness/ perception can be a function of issue evolution, issue features, issue framing and even issue priming. For instance, we know that there is a strong relationship between media and public priorities (e.g., McCombs and Shaw 1972; McCombs and Donald 1993), that media not only shape public opinion but they also influence political agenda setting (e.g., Walgrave and Van Aelst 2006), and that negativity bias is widespread in democratic politics including mass media (e.g., Soroka 2014). Thus, how mental health is covered, framed and primed can have important implications

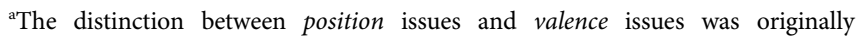
introduced by Donald Stokes. He defines the former as "those that involve advocacy of government actions from a set of alternatives over which a distribution of voter preferences is defined" (Stokes 1963: 373). The latter are "those that merely involve the linking of the parties with some condition that is positively or negatively valued by the electorate" (Stokes 1963: 373). A classic example of a valence issue is corruption.

${ }^{\mathrm{b}}$ According to Entman, to "frame is to select some aspects of a perceived reality and make them more salient in a communicating text, in such a way as to promote a particular problem definition, causal interpretation, moral evaluation, and/or treatment recommendation for the item described" (1993: 52, emphasis in original). Priming "refers to changes in the standards that people use to make political evaluations" (Iyengar and Kinder 1987: 63; but see also Chong and Druckman 2007b: 114-5).
}

for group consciousness, public attitudes toward mental illness and opinion preferences on the issue but also for political elites.

Relatedly, there can be high cross-country and over time variation not only in the saliency but also in the nature (e.g., Soroka 2002) of the mental health issue. While in some countries and at some points mental health may simply be a by-product of the broader health domain, and so conceived more as a "softer", valence issue, in other countries or moments in time it may clash with other issues like crime or employment, and so be perceived as a "harder" issue, more positional in nature, and so more subject to politicization by parties and candidates. Therefore, how the issue emerges and evolves and how parties and candidates take it up and citizens and voters develop preferences on and attitudes toward it are all aspects that require the attention of the political scientist.

\section{To What Signals Does Mental Health Policy Respond?}

A second area of investigation can be subsumed into the following question: to what signals from society does mental health policy respond? A robust finding in the opinion-policy literature shows that policy representation is more likely on high-salience issues. Although research has documented remarkably high levels of policy incongruence, inconsistency and/or frustration, issue salience has nevertheless been depicted as a significant driver of representation and the responsiveness of policy making to public preferences and demands (e.g., Miller and Stokes 1963; Page and Shapiro 1983; Brooks 1985; Monroe 1998; Burstein 2003; Soroka and Wlezien 2010).

Mental health is not commonly conceived as a high-salience issue in electoral terms and is more likely to be important to specific publics and to special interests than to the majority of voters (but this may vary as suggested in the previous subsection). Accordingly, dynamic representation approaches tell us that it seems unlikely that public preferences for mental health would drive change in mental health policy as they would policy relating to more salient issues. ${ }^{c}$

This implies that policy makers can use competing information from other mental health-related alarm signals from society-and not just the majority opinion-when setting their policy. Thus, we could also expect mental health policy to react to mental health-related policy problems and not only-or even-to mental health preferences. This claim is reasonable if we assume that the policy making process is not always motivated by either public preferences/priorities or party ideology, but can also be a response to what have been termed compulsory issues-pressing problems that demand action or that need to be regulated-or to moral panics that generate societal anxieties or fears (e.g., Adler and Wilkerson 2012; Jennings et al., 2020). After all, unlike opposition parties, governing parties need to rule by reacting to problems and responding to issues of broad public concern (Jones et al., 2009; Bonafont and Palau 2011).

${ }^{\mathrm{c}}$ However, note that this assumption is questionable because survey organisations do ask about public attitudes (Burstein 2006), toward mental illness at least in some countries. 
Indeed, this will be more likely if mental health organisation's activity increases over time and if mental illness is perceived more as a diffuse cause-like environmental protection-than a sectional cause favored by a few special interests (e.g., the pharmaceutical industry), civil society and organized interests work as transmission belts between the public and the policy makers, and civil society organisation's and special interests' preferences are aligned with those of the public (e.g., Gilens 2012; Lax and Phillips 2012; Burstein 2014; Rasmussen et al., 2018; Hopkins et al., 2019; Rasmussen and Reher 2019; Bevan and Rasmussen 2020).

Moreover, depending on the extent to which the mental health issue gets mobilized and politicized, the "vocal public" can become another relevant source of information beyond and in combination with the "silent public". Social movement scholars have depicted quite a grim picture of social movements' success in changing policy (for an overview, see Amenta et al., 2010), largely mediated or moderated by political opportunities (e.g., Kriesi et al., 1995; Meyer 2004). In this regard, public opinion can be an important ally for protesters. Research has identified an agenda setting effect of protest (Vliegenthart et al., 2016; see also; Walgrave and Vliegenthart 2012; Hutter and Vliegenthart 2018) and an 'amplification mechanism' and 'joint-effect' model (Agnone 2007; Giugni 2007; Bernardi et al., 2020) that work well in earlier stages of the policy process.

Relatedly, other work suggests that focusing events and external shocks may trigger the mechanisms for policy change (e.g., Clemens 2007; Bernardi et al., 2018). In this regard, the COVID-19 pandemic and its impact on mental wellbeing (O'Connor et al., 2020; Taquet et al., 2020) might potentially act as a trigger for mobilizing the public to demand that governments react by increasing their attention to the issue and introduce minor or major policy changes, depending on the level of responsiveness (e.g., Schumaker 1975), if any. For this purpose, the activity of mental health and patient organisations would be essential for organizing (online and/or offline) mobilization strategies, and the vocal public may amplify the silent public's signal.

Hence, scholars should devote their attention to how various signals from societal actors, policy problems and their interaction in combination with political opportunities may influence political parties' attention and policy changes.

\section{How Does Representation Come About and What are Its Consequences?}

The final set of questions revolves more closely around policy representation. How does representation come about? Are the policy priorities and preferences of people with mental health problems misrepresented? What are the consequences of (mis) representation?

From pledge fulfilment and issue ownership research we know that governing parties are interested in implementing their election mandate (e.g., Klingemann et al., 1994; McDonald et al., 2004) and addressing their partisan issues (e.g., Egan 2013; Green and Jennings 2019). Thus, emphasizing an issue and acquiring ownership of it in partie's election manifestos (e.g., Budge and Farlie 1983; Petrocik 1996) is the first step toward policy representation.
Next, representation can occur directly as a result of rational anticipation and/or electoral turnover (i.e., through elections) (Stimson et al., 1995; Erikson et al., 2002). While the latter is the traditional pathway to representation from election outcomes to public policy and is deeply rooted in the literature on responsible parties (Adams 2001), the former involves politician's responsiveness to changes in public opinion in-between elections. The two ways are related, "assuming incumbent politicians are interested in remaining in office or else motivated to represent our preferences for other reasons" (Wlezien and Soroka 2016: 7).

Moreover, as the thermostatic model (Wlezien 1995; Soroka and Wlezien 2010) postulates, the public must be concerned about an issue in order to notice and respond to policy on that issue. In other words, policy representation is less likely to occur without public responsiveness in the first place. Media policy signals play a crucial role for public responsiveness since the public learns about policy from media policy cues. Indeed, the public tends to respond more strongly to media coverage of policy rather than to policy itself (Neuner, Soroka and Wlezien 2019).

Research on dynamic agenda representation complements research on policy responsiveness to public preferences and tells us that, given the complexity and the amount of public demands, attention is scarce and representation is agenda-specific (e.g., Kingdon 1995; Bevan and Jennings 2014). Policy makers cannot pay attention to all issues-therefore they will select those issues that are most salient to the public (Mortensen et al., 2011)-and institutional friction conditions agenda representation of public priorities (Jones and Baumgartner 2005). Therefore, policy agenda representation of public priorities is a prerequisite for policy responsiveness to public preferences (e.g., Jones et al., 2009).

The vast bulk of research reviewed above pushes us not only to study whether representation on mental health takes place directly, indirectly or thermostatically and whether media policy signals can provide useful informational cues on the issue, but also to focus our attention on policy agendas and the determinants of attention change.

Note that responsiveness is not the only way representation comes about, however. Congruence between citizen's and elite's policy preferences and priorities is equally important. De facto, we can have the former (latter) without the latter (former) (Beyer and Hänni 2018; Lefkofridi 2020) and policy congruence has important consequences for political support (e.g., Reher 2015; Stecker and Tausendpfund 2016). Moreover, research on unequal representation tells us that the policy preferences of different groups are not necessarily represented in the same way and not all groups have the same preferences (e.g., Soroka and Wlezien 2008; Gilens 2009). Evidence of differential responsiveness, inequality in representation, or policy incongruence is found in both the United States (e.g., Bartels 2008; Gilens 2012) and Europe (e.g., Rosset et al., 2013; Peters and Ensink 2015) across income groups and other groups too (e.g., see the work by Reher 2018 on gender and by Pacheco and Ojeda 2019 on health).

Therefore, whether people with mental health problems have different policy priorities and preferences than their healthy counterparts and whether they perceive themselves as a 
cohesive group (see above) should be coupled with whether representatives perceive people with mental health problems as a cohesive group with a common identity and homogenous needs and whether representative's preferences and priorities are congruent with those of people with mental illness. ${ }^{\mathrm{d}}$

Further, it is likely that the mental health-participation gap identified in previous research can both influence and be influenced not only by policy incongruence but also by lack of symbolic and descriptive representation. That is, if people with mental illness think that representatives, especially those experiencing the same problems, do not 'stand for' them, then they will feel less represented and, in turn, less motivated to participate in politics. The fact that politicians pay more attention to the opinions of voters than to those of non-voters (Griffin and Newman 2005) may further dampen feelings of efficacy and of perceived responsiveness and representation (e.g., Esaiasson et al., 2017).

Finally, on the one hand, representation can occur beyond descriptive (Pitkin 1967) or gyroscopic (Mansbridge 2003) forms-e.g., by surrogation (Mansbridge 2003), justification (Rehfeld 2009) or even by claim (Saward 2006)-and representatives who resemble those being represented or have shared similar experiences do not always represent them better. On the other hand, representative's disclosure of a mental health problem may have important implications for public attitudes toward mental illness (Loewen and Rheault 2019). Thus, it is worth studying what kind of opinion people with mental illness have of their representatives and assess how public opinion perceives representatives with mental health problems.

Certainly, there are many more interesting questions to ask in relation to political representation and mental health that go beyond what I have outlined above. For instance, on the citizen side, I have not touched upon other potentially relevant issues like political institutions or electoral incentives as moderators of representation, or potential voting restrictions for some severe mental illnesses. On the candidate side, electoral constraints and other barriers at the recruitment level can also be important. Yet I hope what I have discussed here can be a useful agenda for future research.

Below I start addressing empirically one question from the second major area: do policy makers address public preferences for mental health or respond to policy problems relating to mental health?

\section{DOES MENTAL HEALTH SPENDING RESPOND TO PUBLIC PREFERENCES OR TO MENTAL HEALTH-RELATED PROBLEMS?}

The second major area described above asks about the societal signals to which mental health policy responds. Addressing this question can illustrate how policy representation takes

\footnotetext{
${ }^{\mathrm{d}}$ Note that if different groups want the same policy or care about the same issue, then it does not really matter which group policymakers represent, as will they both get representation.
}

place. Here, I rely on the thermostatic model of representation (Soroka and Wlezien 2010) which predicts an over-time dynamic between public opinion and policy: this year's preferences influence policy for next year, which in turn influences the next year's preferences, and so on. If representation works thermostatically, when the public wants more (less) policy, then governments provide more (less) policy, and the public, in turn, readjusts its preferences and wants less (more) policy, and so on.

It is interesting to see whether the same dynamic can be applied in the same way to other signals from society beyond public preferences-here I consider policy problems. If policy reacts thermostatically to problems then we should observe that when problem magnitude increases policy makers react as problem solvers and provide more policy. This is quite reasonable in a case such as mental health as discussed above and its possibility is conceived of in dynamic representation models (Stimson et al., 1995, Figure 1, p. 546). However, if we recall the low saliency of mental health and assume that policy makers are primarily motivated by strategic considerations, that might not be the case unless they factor in valence considerations in their policy decisions or find it beneficial to instrumentally tackle policy problems to gain votes or keep office (e.g., Strøm 1990). Yet this remains an empirical question and below I provide an empirical test of whether mental health policy attends thermostatically to competing signals from society.

Such an exercise requires the collection of over time data on policy, public opinion, and issue-related problems. Data for all these indicators are available for 20 years in England. Aside from data availability, England is an interesting context to study. Although the Labor Party mentioned the need to increase support for mental illness in its 2010 election manifesto, it is the Conservative Party, in the Coalition government and subsequently, which carried forward plans for investment in mental health and reform of the Mental Health Act. What makes the case even more interesting is that, while the Labor Party in Britain can be safely considered the "owner" of the health issue, issue ownership is not really established for mental health (see Bernardi 2020).

I followed previous research on the thermostatic model which uses spending as a policy indicator. Mental health services are provided as a mix of community-based and hospital-based services (Thornicroft and Tansella 2004) and calculating their costs is not an easy task (Knapp and Beecham 1990). Due to lack of extensive over time data on NHS spending on mental health, I collected data on net current expenditure on adults (18-64) with mental health needs from the social services departments of Councils with Adult Social Services Responsibilities (CASSR) in England. Although this is only a limited portion in comparison with NHS spending on mental health, the data account for people with severe mental health conditions and span from 1994-95 to 2013-14 and so offer a reasonably long time series for testing my hypotheses. The data are updated on a yearly basis and provided by the Health and Social Care Information Center (HSCIC) of the Office for National Statistics and available through NHS Digital (more details 

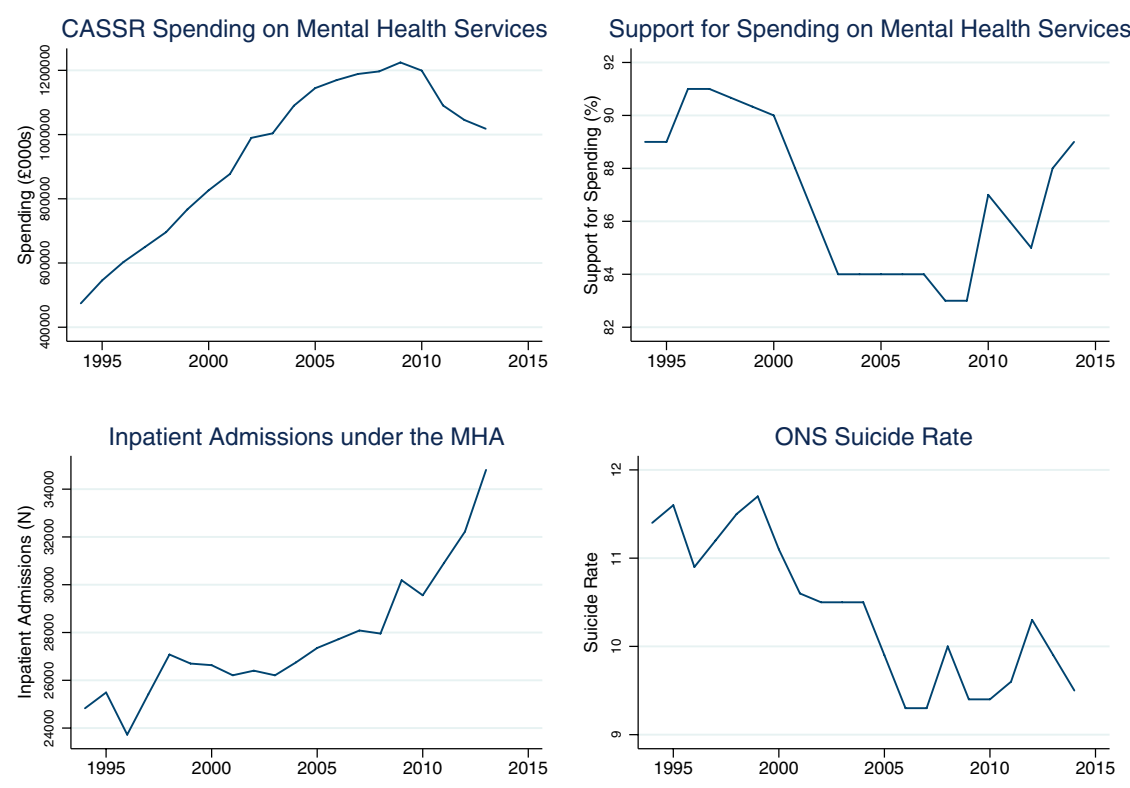

FIGURE 1 | Spending on mental health services in England, public preferences and mental health-related policy problems.

about the data are provided in Section S1 of the Online Appendix). ${ }^{\mathrm{e}}$ I use net and not gross expenditure because it is more suitable for analyzing the effect of other factors on spending on mental health services as it focuses on adult social care funded by local authorities and removes capital charges and external income, and is therefore not impacted by changes in client contributions and income from the NHS. As the expenditure the HSCIC reports is the local authority spending, this could be on community and hospital provision.

During this period, a yearly average of about $£ 940$ million was spent on mental health in England (the data were adjusted for inflation using the Consumer Price Index taken from the Office for National Statistics) (standard deviation = c. $£ 243$ million). Figure 1 shows that spending increases for most of the reference period, with a decline starting in 2010 (Olesen 2012), which relates to the introduction of austerity measures by the Coalition government. In the last year covered in this study, spending on adults (18-64) with mental health needs represents only $6 \%$ of total gross expenditure on social services (HSCIC 2014).

\section{Preferences for Spending Support}

To measure public preferences on mental health services, ideally a survey question that asks respondents about support for spending

${ }^{e}$ The data provided by HSCIC include expenditures on the following items: assessment and care management (G1), nursing care placements (G2.1), residential care placements (G2.2), supported and other accommodation (G4), direct payments (G8), home care (G5), day care/day services (G6), fairer charging-community services (G7), equipment and adaptations (G9), meals (G10), and other non-residential costs (G11). Since expenditure on supporting people (G13) is only available from 2003-4, the total expenditure (G12) used excludes that item. is needed. Such a question was asked repeatedly during the period 1994-2014 in the Department of Health Mental Illness Surveys (see Section S2 of the Online Appendix for more details about the survey) (TNS BMRB 2015). Specifically, the question asks how much the respondent agrees with the following statement: "Increased spending on mental health services is a waste of

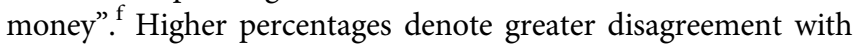
the statement, in other words, greater support for spending. Unfortunately, the survey was not conducted on a yearly basis throughout the entire time span. Data are missing for 1998, 1999, $2001,2002,2004,2005$, and 2006. Linear interpolation is used to fill these gaps and make the series continuous. Though not perfect, of course, this solution has been adopted in previous research on opinion preferences and policy representation (Jennings and Wlezien 2015).

The top-right panel in Figure 1 plots the interpolated series. The English public expresses strikingly high and stable over time levels of support for spending on mental health (mean $=86.9 \%$ and std. dev. $=2.9 \%$ ). There is, however, a significant drop

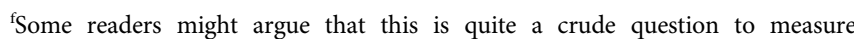
preferences, more extreme than the more neutral question on spending preferences that we are more accustomed to, as asked, for instance, in the General Social Survey. Unfortunately, the longitudinal survey does not include this question but provides an alternative that asks respondents how much they agree with the statement "There are sufficient existing services for people with mental illness". Changes in these two variables are strongly correlated ( $r=0.58)$. Therefore, in Supplementary Table S2 I have re-estimated my model replacing the support for spending variable used in the article with a variable labeled Change in Preferences Index $(t-1)$ which is the mean of the two variables. Results are in line with the ones in the paper, except that the coefficient on the alternative variable falls short of statistical significance in the OLS model with LDV. 
between 2000 and 2003. This drop is consistent with other unfavorable changes in public attitudes toward mental illness in England during that period. Beginning in the late 1990s a series of anti-stigma campaigns were run across the United Kingdom, beginning with the Royal College of Psychiatrists "Changing Minds" campaign in England between 1998 and 2003 and the Scottish Government 'see me' campaign starting in 2002 (Mehta et al., 2009). However, Mehta et al. (2009: 278) explain the drop by the fact that, at the same time as the anti-stigma campaigns, negative media attention linking mental illness to violence intensified-partly due to the reporting about reform of mental health legislation in England since 1998 and the publication of the "controversial" 2002 Mental Health Bill by the Department of Health in England, which proposed extended powers of compulsory detention of patients and the introduction of a form of community treatment order.

This evidence, in addition to growing evidence-based research about reducing stigma and discrimination, encouraged the development of England's national Time to Change anti-stigma campaign, funded in 2007 but only started in 2009 (Evans-Lacko et al., 2013a). Public attitudes did not improve consistently on all dimensions: significant improvements have been noted in prejudice and exclusion but not in tolerance and support for community care (Evans-Lacko et al., 2014). Also, after the program was launched there was a significant increase in the proportion of anti-stigmatizing articles between 2008 and 2011 but not a concomitant decrease in stigmatizing articles (Thornicroft et al., 2013). Nonetheless, the graph shows some increase in support for spending since 2010.

\section{Policy Problems}

To measure mental health-related policy problems, I compiled data on two different indicators which vary in terms of problem gravity. ${ }^{\text {g }}$ First, I compiled data on formal admissions to NHS facilities and independent hospitals registered to detain patients under the Mental Health Act (1983) and other legislation. Data providers changed over time (see Section S4 of the Online Appendix for details), but it was possible to construct a comparable series for the same period as spending. The data are plotted in the bottom-left panel of Figure 1 and show a rapid increase in detentions since the 2002 Mental Health Bill.

Second, I include a measure of the suicide rate because of its crucial connection with mental health problems and stigma (e.g., Schomerus et al., 2015). I rely on age-standardized suicide rates available from the Office for National Statistics (see Section S5 of the Online Appendix for more details). Plotted in the bottom-right panel of Figure 1, suicide rates in England range from 9.3 to 11.7 and show a declining trajectory beginning in the early 1990s (McClure 2000)-the small peak in 2008 is related to the economic recession (Barr et al., 2012; Evans-Lacko et al.,

gI also collected data on mental wellbeing from the General Health Questionnaire (GHQ), commonly used to measure mental health in population samples. An aggregated measure based on the 12-item GHQ scale is available between 1991 and 2009 in the British Household Panel Survey and subsequently the United Kingdom Household Longitudinal Study. However, since there is virtually no over-time variation in the variable (it ranges from 11.0 to 11.4, see Supplementary Table S1), I excluded this problem indicator from the empirical analysis. 2013b). Research indicates that the decline in suicide rates is in part related to a reduction in poisoning with car exhaust gas (due to an increased use of vehicles with catalytic converters) and a decline in unemployment and divorce. However, there is little evidence of a relationship with reductions in alcohol use and increases in prescription of antidepressants (McClure 2000; Biddle et al., 2008).

Overall, while admissions have tended to increase since the late 1990s, support for spending and suicide rates both seem to partially move together, though the trends became less similar after 2009. While support for spending decreases between the early 2000s and 2009 (the Time to Change anti-stigma campaign's effects would be visible only a couple of years after its launch), the suicide rate is also lower between 1999 and 2007. However, as suggested above, there might be other factors influencing the declining trend in suicide rate that are not necessarily linked to stigma attitudes.

\section{METHODS}

To test whether spending on mental health responds to spending support and mental health policy-related problems, I follow previous research on government responsiveness (e.g., Soroka and Wlezien 2010) that estimates change in policy as a function of relative preferences and partisanship. Here I extend this model by including covariates for mental health-related problems. As my data are time-series data, I first test whether the variables are stationary since results obtained using non-stationary series may be spurious and lead to flawed hypothesis tests (Beck 2008). Evidence from a Dickey-Fuller test suggests that the null hypothesis that the series contains a unit root cannot be rejected for spending on mental health services, spending preferences, inpatient admissions and suicide rate. ${ }^{\text {h }}$ For this reason, I estimate these variables in changes and not in levels. The independent variables are estimated at time $(t-1)$ to establish time order in the opinion-policy relationship (e.g., Page and Shapiro 1983) and reflect budgetary policy making (e.g., Soroka and Wlezien 2010).

${ }^{\mathrm{h}}$ For spending preferences, inpatient admissions and suicide rate, the Dickey-Fuller test statistic does not surpass any of the $t$ distribution critical values and MacKinnon's $p>0.10$, and so it can be concluded that the sequences are not stationary; for mental health spending the Dickey-Fuller test statistic only surpasses the 10 percent critical value of the $t$ distribution but not the $5 \%$ and $1 \%$ critical values.

${ }^{i}$ Note that one criticism that first-difference models receive is that, although offering a solution to stationarity and serial correlation problems, these benefits come at the cost of long-term trends, whereby the long-term effects of the independent variables are differenced out. Ideally, an unrestricted error correction model including independent variables both in levels and changes would be superior (De Boef and Keele 2008), but unfortunately such a model is too demanding and can be estimated only with the availability of longer time-series. ${ }^{j}$ Although estimating public opinion at time $(t-1)$ is customary in studies of dynamic representation, it might still be the case that policy responds to preferences or problems with a different lag structure and to current changes rather than past changes. Given that the very small number of observations in my data set prevents the estimation of more sophisticated error correction models, I run two alternative model specifications, with preferences and problems at time $(t)$ and $(t-2)$. The analyses are reported in Supplementary Table S4 and I find no evidence that spending responds to preferences or problems in any of the alternative specification. 
In the next section, I estimate the model reported in Eq. 1:

$$
\begin{aligned}
\text { Change in Policy }(\mathrm{t})= & \mathrm{b} 1[\text { Change in Preferences }(\mathrm{t}-1)] \\
& +\mathrm{b} 2[\text { Change in Admissions }(\mathrm{t}-1)] \\
& +\mathrm{b} 3[\text { Change in Suicide Rate }(\mathrm{t}-1)] \\
& +\mathrm{b} 4[\text { Partisanship }(\mathrm{t}-1)]
\end{aligned}
$$

My dependent variable, Change in Policy $(t)$, measures the change in spending between the current year and the previous year. Coefficient b1 estimates the effect of public support for spending whereas coefficients b2 and b3 estimate the effects of the two policy problems. If mental health spending by local authorities responds to public and policy signals in the expected direction, I should expect a positive and significant coefficient on these variables. To account for the possibility that spending represents government priorities rather than public opinion's signals, I also control for the partisanship of the national government, coefficient b4, with a dummy variable coded one if the government was from the Labor Party and 0 otherwise. It is important to control for government partisanship in order to capture indirect representation and minimize the risk of a spurious relationship between opinion and policy. As Figure 1 shows, we see a sharp decline in mental health spending roughly at the same time that the Coalition government took over and the global financial crisis hit. Thus, the partisanship variable not only accounts for the Coalition taking office and implementing austerity measures, but indirectly also controls for the potential impact of the global financial crisis. ${ }^{\mathrm{k}}$

Finally, I need to test for autocorrelation in the data. Although estimating the dependent variable in changes partly accounts for autocorrelation problems, graphical plots of correlation and partial autocorrelation functions of the dependent variable as well as Durbin-Watson and Breusch-Pagan post-estimation tests for autocorrelation of the model presented in Eq. 1 suggest that there is still some evidence of autocorrelation in the data. For this reason, I prefer to be on the safe side and estimate my model using the Prais-Winsten estimator, which is based on the feasible generalized least squares (FGLS) method and preferable for small samples compared to ordinary least squares (OLS) regression with lagged dependent variable (LDV) (see Wooldridge 2002, Ch. 12; Fortin-Rittberger 2014). ${ }^{1}$ Results are reported in Table 1

${ }^{\mathrm{k}}$ As a robustness check, I re-estimated my analyses including a dummy variable for 2009, which is when we start observing the decline in mental health spending. The variable was not statistically significant and results did not change. This analysis is reported in Supplementary Table S5.

${ }^{1}$ The Prais-Winsten transformation method assumes that the errors follow an $\mathrm{AR}(1)$ process and that covariates, in my case preferences and problems, are strictly exogenous. Unlike the OLS regression with LDV which allows all components of the LDV to influence the dependent variable at time $(t)$, the Prais-Winsten method uses a different approach and only estimates the effects of the residual component. I present my analyses with the Prais-Winsten method in the paper and with OLS with LDV in the Online Appendix (Supplementary Table S3). Results are consistent, with the only difference being that government partisanship is positive and significant. The LDV is negative and significant across models, which in combination with a positive and significant intercept, implies some evidence of a regression to the mean effect. below. Descriptive statistics for all variables included in the analyses are reported in Supplementary Table S1 of the Online Appendix.

\section{RESULTS}

Given the small number of observations at my disposal, I present models with one covariate at a time and a control for government partisanship. Given that the independent variables are estimated in lagged changes, the number of observations in the analyses is slightly lower $(\mathrm{N}=18)$. The Durbin-Watson statistic is reported at the bottom of the table and in the Prais-Winsten method is close to 2 , suggesting that the approach is successful in correcting for autocorrelation. The adjusted $R^{2}$ is higher in the preferences model.

The coefficient on the Partisanship $(t-1)$ variable is positive in all models, suggesting that Labor governments are associated with higher local spending on mental health services. However, the coefficient is only barely significant in one of the three models (But note that in the models using the OLS approach with LDV reported in the Online Appendix, the variable appears to be always positive and significant suggesting evidence of in direct representation.)

Let us move to the results on the key explanatory variables. I first consider the coefficient on the Change in Preferences $(t-1)$ variable (model 1), which as per the thermostatic model (and dynamic representation models in general) would be the key component of direct representation. The coefficient is statistically significant at $p<0.05$, suggesting that there is an association between change in spending and lagged change of opinion preferences. However, this relationship is negative-i.e., public opinion wants more (less) policy on mental health but gets less (more). ${ }^{\mathrm{m}}$ Next, I move to the two indicators of policy problems included in the analysis. There is no evidence that change in mental health spending by local authorities is associated with changes in lagged inpatient admissions (model 2) or lagged suicide rate (model 3), suggesting that spending does not respond to changes in the incidence of mental health-related problems.

Certainly, caution is warranted, and more data are needed to be able to confirm these initial findings.

\section{DISCUSSION}

In England public concern about mental health increased by 11 percentage points in 2017, with $32 \%$ of the English public

\footnotetext{
mAlthough this paper's aim is not specifically about testing Wlezien's (1995) thermostatic model, it is nonetheless interesting to comment on the public responsiveness component of the model. When simply regressing current levels of preferences on current levels of spending I observed a negative and significant coefficient on the spending variable, which holds when including previous levels of preferences. However, given the above discussion on stationarity it might still be the case that the relationship is spurious. Therefore, I re-estimated the relationship in changes, in various combinations, none of which leads to a significant coefficient on the spending variable.
} 
TABLE 1 | Policy representation on mental health in England.

\begin{tabular}{lccc}
\hline & Model (1) & Model (2) & Model (3) \\
\hline $\begin{array}{l}\text { Change in Preferences } \\
(t-1)\end{array}$ & $-15053^{*}(6359)$ & & \\
Change in Admissions & & $-7(9)$ & \\
$(t-1)$ & & & \\
Change in Suicide Rate & & & $3344(20765)$ \\
$(t-1)$ & & & \\
Partisanship (t-1) & $8222(29583)$ & $56383^{\dagger}(29776)$ & $46170(28469)$ \\
Constant & $15345(27722)$ & $-8975(24731)$ & $-4946(26056)$ \\
$R^{2}$ & 0.37 & 0.21 & 0.17 \\
Adj $R^{2}$ & 0.29 & 0.10 & 0.05 \\
DW (original) & 0.84 & 1.10 & 0.97 \\
DW (transformed) & 2.40 & 2.05 & 2.17 \\
$N$ & 18 & 18 & 18 \\
Start & 1995 & 1995 & 1995 \\
End & 2013 & 2013 & 2013 \\
\hline
\end{tabular}

${ }^{* *} \mathrm{p} \leq .01,{ }^{*} \mathrm{p} \leq .05,+\mathrm{p} \leq .10$, two-tailed tests.

Note: the dependent variable in these analyses is Change in Policy (t) (£000s).

considering mental health as the most worrying public health issue, second only to cancer (at 41\%) (Ipsos Public Affairs 2017). English citizens have been expressing an extremely high and stable level support for more spending on mental health in polls, reaching over $90 \%$ in some years (TNS BMRB 2015). Arguably, such a high level of public agreement makes the issue of mental health in England a quasi-valence issue.

Thus, from survey data, we know that mental health support in England is high and stable and that mental health is more important than many other health issues. Yet, in spite of these figures, we do not know how important mental health is in comparison with policy issues outside the health domain. We do know, though, that mental health can hardly be considered a socalled "big-ticket" issue ${ }^{\mathrm{n}}$ in electoral terms, even though its prevalence and socioeconomic burden make the issue of great importance not only for sufferers and their families but also for scholars and, hopefully, policy makers.

The empirical analysis presented above shows some evidence of policy misrepresentation, since the relationship between support for spending on mental health services and spending by local authorities is negative: when the public wants more (less) spending on mental health, it gets less (more). However, as noted above, support for spending on mental health services remains starkly high in opinion polls in the time covered by this study. In addition, these data show no evidence of an association between spending and policy problems.

These findings make a number of contributions. Firstly, they suggest that focusing on major policy domains risks overestimating the proportion of policy domains in which there is representation (Page 2002; Burstein 2006). The data used here seem to support this claim. Secondly, most of the research on dynamic representation at local levels was based on analyses from the United States (e.g., Pacheco 2013; Caughey and Warshaw 2018). This study contributes to

${ }^{\mathrm{n}} \mathrm{I}$ thank Mark Franklin for the expression. extending this work to the European context, even if for one case only. Thirdly, my analysis represents a first attempt to move empirical research on mental health and political behavior beyond political engagement.

There are some limitations that future research needs to address. First, studying mental health policy responsiveness in one country for a limited time span and with only a portion of mental health spending raises questions about the extent to which these findings apply to other contexts. Although collecting data on policy, preferences and problems across countries and over time is a difficult task, comparative research is needed to reach a greater understanding of mental health policy representation.

Second, due to lack of a longer time series on stigma attitudes, this study could not test for the effect of public stigma on change in mental health spending, which would be another important factor to account for. Support for spending on mental health among the English public suggests that mental illness stigma, though globally important, may not be as dramatic as in lower-income countries. Comparative research is needed to better understand whether higher (lower) levels of stigma are associated with greater (lesser) policy representation and whether mental health policy is more (less) likely to be responsive in higher-income (lowerincome) countries.

Third, although information on public support for spending was included, this analysis could not investigate the role that public perceptions of policy problems and mental health organisations might play in influencing policy change. The significance of voters' perceptions of policy problems is well known in the political behavior literature, and these perceptions are sometimes even more important than the problems themselves. Parties extensively monitor the public mood in order to respond to it or even anticipate it. Hence, future research would need to incorporate public perceptions of policy problems into the picture. In addition, future research should also collect data on mental health organisation's activity and test their direct and conditional effect on policy change. This is particularly important in the case of mental illness where public ignorance, prejudice and discrimination may condition how public opinion perceives policy problems such as the ones analyzed here.

\section{CONCLUSION}

This article offered a roadmap for research on the political representation of mental health by focusing on decades of research on the relationship between public opinion and public policy. Though not exhaustive, the article set forth a wide number of research questions involving mental health and political (especially policy-based) representation organized across three areas of investigation: 1) opinion formation and issue emergence and evolution, 2) multiple and complementary societal signals that can influence policy makers' issue attention and policy change, and 3) different conceptions of representation and their consequences for public attitudes and political participation. 
The hope is that this paper with its call for action and its negative finding on policy representation in England will push funders to invest more resources and the academic community to collect more data. The goal is noble and valuable: to improve our knowledge and understanding of the political representation of mental health and to propose interventions that will help overcome stigma and participation challenges that undermine political equality (Dahl 1956) as one of the key principles of democracy.

\section{DATA AVAILABILITY STATEMENT}

The original contributions presented in the study are included in the article/Supplementary Material, further inquiries can be directed to the corresponding author.

\section{AUTHOR CONTRIBUTIONS}

The author confirms being the sole contributor of this work and has approved it for publication.

\section{REFERENCES}

Adams, J. (2001). Party competition and responsible party government: a theory of spatial competition based upon insights from behavioral voting research. Ann Arbor: University of Michigan Press, 233.

Adler, S. E., and Wilkerson, J. D. (2012). Congress and the politics of problem solving. New York, NY: Cambridge University Press, 262.

Agnone, J. (2007). Amplifying public opinion: the policy impact of the U.S. Environmental movement. Soc. Forces 85 (4), 1593-1620. doi:10.1353/sof. 2007.0059

Amenta, E., Neal, C., Chiarello, E., and Su, Y. (2010). The political consequences of social movements. Annu. Rev. Sociol. 36 (April), 287-307. doi:10.1146/ annurev-soc-070308-120029

Barr, B., Taylor-Robinson, D., Scott-Samuel, A., McKee, M., and Stuckler, D. (2012). Suicides associated with the 2008-10 economic recession in England: time trend analysis. BMJ 345, e5142. doi:10.1136/bmj.e5142

Bartels, L. (2008). Unequal democracy. New York, NY: Russell Sage, 74.

Baumgartner, F. R., De Boef, S., and Boydstun, A. E. (2008). The decline of the death penalty and the discovery of innocence. New York, NY: Cambridge University Press, 292.

Baumgartner, F. R., and Jones, B. D. (2010). Agendas and instability in American politics. Chicago and London: University of Chicago Press, 298.

Beck, N. (2008). "Time-series cross-section methods," in The oxford handbook of political methodology. David collier. Editors J. M. BoxSteffensmeier and H. E. Brady (Oxford, United Kingdom: Oxford University Press), 475-493.

Bernardi, L., Bischof, D., and Wouters, R. (2020). The public, the protester, and the bill: do legislative agendas respond to public opinion signals? J. Eur. Publ. Pol. 0 (0), 1-22. doi:10.1080/13501763.2020.1729226

Bernardi, L., and Johns, R. (2020). Depression and attitudes to change in referendums: the case of Brexit. Eur. J. Polit. Res. doi:10.1111/1475-6765.12398

Bernardi, L., and Johns, R (N.d). "Depression and negativity bias in democratic politics," in International society of political psychology annual conference, Lisbon, Portugal, July 12-15, 2019.

Bernardi, L., Mattila, M., Papageorgiou, A., and Lauri Rapeli, N. D. (N.d.). "Down but not yet out: depression, political efficacy and voting," in Paper presented at the democracy, elections and citizenship research group seminar series. Universitat Autònoma de Barcelona

\section{ACKNOWLEDGMENTS}

The empirical part of this paper was presented at the "Democracy, Elections and Citizenship" (DEC) Workshop at the Universitat de Barcelona (July 3, 2018) and at the Comparative Agendas Project annual conference in Amsterdam (4-6 July 2018). I thank the participants for their comments. I also thank Christopher Wlezien, Robert Johns, Stefanie Reher, James Adams, Mark Franklin, Will Jennings, Shaun Bevan, Patrick Corrigan and Christopher Dowrick for their feedback and discussion on various aspects of this paper and Sarah Liley at NHS Digital for her invaluable assistance with the spending data. Finally, I am deeply grateful to the editors of the special issue and the reviewers for their comments and for encouraging me to take on the enterprise. All errors remain mine.

\section{SUPPLEMENTARY MATERIAL}

The Supplementary Material for this article can be found online at: https://www.frontiersin.org/articles/10.3389/fpos.2020.587588/ full\#supplementary-material.

Bernardi, L., Morales, L., Lühiste, M., and Bischof, D. (2018). The effects of the Fukushima disaster on nuclear energy debates and policies: a two-step comparative examination. Environ. Polit. 27 (1), 42-68. doi:10.1080/ 09644016.2017.1383007

Bernardi, L. (2020). Depression and political predispositions: almost blue? Party Politics. doi:10.1177/1354068820930391

Bevan, S., and Jennings, W. (2014). Representation, agendas and institutions. Eur. J. Polit. Res. 53 (1), 37-56. doi:10.1111/1475-6765.12023

Bevan, S., and Rasmussen, A. (2020). When does government listen to the public? Voluntary associations and dynamic agenda representation in the United States. Pol. Stud. J. 48 (1), 111-132. doi:10.1111/psj.12231

Beyer, D., and Hänni, M. (2018). Two sides of the same coin? Congruence and responsiveness as representative democracy's currencies. Pol. Stud. J. 46, S13-S47. doi:10.1111/psj.12251

Biddle, L., Brock, A., Brookes, S. T., and Gunnell, D. (2008). Suicide rates in young men in England and Wales in the 21st century: time trend study. Bmj 336 (7643), 539-542. doi:10.1136/bmj.39475.603935.25

Bonafont, C., and Palau, A. M. (2011). Assessing the responsiveness of Spanish policymakers to the priorities of their citizens. W. Eur. Polit. 34 (4), 706-730. doi:10.1080/01402382.2011.572388

Boydstun, A. E. (2013). Making the news: politics, the media, and agenda setting. Chicago, United States: University of Chicago Press, 240.

Brooks, J. E. (1985). Democratic frustration in the anglo-American polities: a quantification of inconsistency between mass public opinion and public policy. West. Polit. Q. 38 (2), 250-261. doi:10.2307/448628

Budge, I., and Farlie, D. J. (1983). Explaining and predicting elections: issue effects and party strategies in twenty-three democracies. London, United Kingdom: Allen and Unwin, 226.

Burden, B. C., Fletcher, J. M., Herd, P., Jones, B. M., and Moynihan, D. P. (2017). How different forms of health matter to political participation. J. Polit. 79 (1), 166-178. doi:10.1086/687536

Burstein, P. (2014). American public opinion, advocacy, and policy in congress: what the public wants and what it gets. New York, NY: Cambridge University Press, 233.

Burstein, P. (2010). "Public opinion, public policy, and democracy," in In Handbook of politics. Editors K. Leicht and C. Jenkins (New York, NY: Springer US), 63-80.

Burstein, P. (2006). Why estimates of the impact of public opinion on public policy are too high: empirical and theoretical implications. Soc. Forces 84, 2273-2289. doi:10.1353/sof.2006.0083 
Carmines, E. G., and Stimson, J. A. (1993). "On the evolution of political issues," in In agenda formation. Editor W. H. Riker (Ann Arbor: The University of Michigan Press), 151-168.

Caughey, D., and Warshaw, C. (2018). Policy preferences and policy change: dynamic responsiveness in the American states, 1936-2014. Am. Polit. Sci. Rev. 112 (2), 249-266. doi:10.1017/S0003055417000533

Chong, D., and Druckman, Ja. N. (2007a). A theory of framing and opinion formation in competitive elite environments. J. Commun. 57 (1), 99-118. doi:10.1111/j.1460-2466.2006.00331.x

Chong, D., and Druckman, J. N. (2010). Dynamic public opinion: communication effects over time. Am. Polit. Sci. Rev. 104 (4), 663-680. doi:10.1017/ S0003055410000493

Chong, D., and Druckman, J. N. (2007b). Framing theory. Annu. Rev. Polit. Sci. 10, 103-126. doi:10.1146/annurev.polisci.10.072805.103054

Clemens, E. S. (2007). Toward a historicized sociology-theorizing events, processes, and emergence. Annu. Rev. Sociol. 33, 527-549. doi:10.1146/ annurev.soc.33.040406.131700

Corrigan, P. (2004). How stigma interferes with mental health care. Am. Psychol. 59, 614-625. doi:10.1037/0003-066X.59.7.614

Corrigan, P. W., Roe, D., and Tsang, H. W. H. (2011). Challenging the stigma of mental IllnessLessons for therapists and advocates. Chichester, West Sussex: Wiley-Blackwell, 253.

Corrigan, P. W., Markowitz, F. E., and Watson, A. C. (2004). Structural levels of mental illness stigma and discrimination. Schizophr. Bull. 30, 481-491. doi:10. 1093/oxfordjournals.schbul.a007096

Couture, J., and Breux, S. (2017). The differentiated effects of health on political participation. Eur. J. Publ. Health 27 (4), 599-604. doi:10.1093/eurpub/ ckw245

Dahl, R. A. (1956). Preface to democratic theory. Chicago, United States: University of Chicago Press, 155.

De Boef, S., and Keele, L. (2008). Taking time seriously. Am. J. Polit. Sci. 52 (1), 184-200. doi:10.1037//0003-066x.54.3.165

Egan, P. J. (2013). Partisan priorities. How issue ownership drives and distorts American politics. New York, NY: Cambridge University Press, 264.

Entman, R. (1993). Framing: toward a clarification of a fractured paradigm. J. Commun. 43 (3), 51-58. doi:10.1111/j.1460-2466.1993.tb01304.x

Erikson, R. S., Mackuen, M. B., and Stimson, J. A. (2002). The macro polity. Cambridge, United Kingdom: Cambridge University Press, 469.

Esaiasson, P., Gilljam, M., and Persson, M. (2017). Responsiveness beyond policy satisfaction: does it matter to citizens? Comp. Polit. Stud. 50 (6), 739-765. doi:10.1177/0010414015626445

Evans-Lacko, S., Henderson, C., and Thornicroft, G. (2013a). Public knowledge, attitudes and behaviour regarding people with mental illness in England 20092012. Br. J. Psychiatr. Suppl. 55 (Suppl. 55), s51-s57. doi:10.1192/bjp.bp.112. 112979

Evans-Lacko, S., Knapp, M., McCrone, P., Thornicroft, G., and Mojtabai, R. (2013b). The mental health consequences of the recession: economic hardship and employment of people with mental health problems in 27 European countries. PloS One 8 (7), e69792. doi:10.1371/journal.pone. 0069792

Fortin-Rittberger, M. (2014). "Jessica.Time-Series cross-section," in Henning best and christof wolf. The SAGE handbook of regression analysis and causal inference London, United Kingdom: Sage, 424.

Gilens, M. (2012). Affluence and influence. Princeton, NJ: Princeton University Press, 312.

Gilens, M. (2009). Preference gaps and inequality in representation. PS Polit. Sci. Polit. (April), 335-341. doi:10.1017/S1049096509090441

Giugni, M. (2007). Useless protest? a time-series analysis of the policy outcomes of ecology, antinuclear, and peace movements in the United States, 1977-1995. Mobil. Int. Q. 12 (1), 53-77. doi:10.17813/ maiq.12.1.b05j1087v7pxg382

Goodwin, S. (1997). Comparative mental health policy: from institutional to community care. London, United Kingdom: Sage, 192.

Green, J., and Jennings, W. (2019). Party reputations and policy priorities: how issue ownership shapes executive and legislative agendas. Br. J. Polit. Sci. 49 (2), 443-466. doi:10.1017/S0007123416000636

Griffin, J. D., and Newman, B. (2005). Are voters better represented? J. Polit. 67 (4), 1206-1227. doi:10.1111/j.1468-2508.2005.00357.x
Gustavsson, A., Svensson, M., Jacobi, F., Allgulander, C., Alonso, J., and Beghi, E. (2011). Cost of disorders of the brain in Europe 2010. Eur. Neuropsychopharmacol. 21, 718-779. doi:10.1016/j.euroneuro.2011.08.008

Holmes, E. A., O'Connor, R. C., Perry, V. H., Tracey, I., Wessely, S., and Arseneault, L. (2020). Multidisciplinary research priorities for the COVID-19 pandemic: a call for action for mental health science. Lancet Psych. 7 (6), 547-560.

Hopkins, V., Klüver, H., and Pickup, M. (2019). The influence of cause and sectional group lobbying on government responsiveness. Polit. Res. Q. 72 (3), 623-636. doi:10.1177/1065912918796326

HSCIC (2014). Personal social services: expenditure and unit costs, England, 2013-14 final release. Available at: https://data.gov.uk/dataset/de8c23063d21-4129-ad82-5dcaa5d0b134/personal-social-services-expenditure-andunit-costs-england (Accessed Apirl 08, 2014).

Hutter, S., and Vliegenthart, R. (2018). Who responds to protest? Protest politics and party responsiveness in Western Europe. Party Polit. 24 (4), 358-369. doi:10.1177/1354068816657375

Ipsos Public Affairs (2017). Public health England, public awareness and opinion survey 2017. Available at: https://www.ipsos.com/sites/default/ files/ct/publication/documents/2017-12/phe-public-opinionawareness_2. pdf (Accessed July 12, 2017).

Iyengar, S., and Kinder, D. R. (1987). "News that matters," in Television and American opinion. Chicago, United States: Chicago University Press, 216.

Iyengar, S., and Reeves, R. (1997). Do the media govern? Politicians, voters and reporters in America. Thousand Oaks, CA: Sage, 488.

Jennings, W., Farrall, S., Gray, E., and Hay, C. (2020). Moral panics and punctuated equilibrium in public policy: an analysis of the criminal justice policy agenda in Britain. Pol. Stud. J. 48 (1), 207-234. doi:10.1111/ psj.12239

Jennings, W., and Wlezien, C. (2015). Preferences, problems and representation. Polit. Sci. Res. Methods 3 (3), 659-681. doi:10.1017/psrm.2015.3

Jones, B. D., and Baumgartner, F. R. (2005). The politics of attention: how government prioritizes problems. Chicago, United States: University of Chicago Press, 316.

Jones, B. D., Larsen-Price, H., and Wilkerson, J. (2009). Representation and American governing institutions. J. Polit. 71 (1), 277-290. doi:10.1017/ S002238160809018X

Kellstedt, Paul. M. (2003). The mass media and the dynamics of American racial attitudes. New York, NY: Cambridge University Press, 115.

Kingdon, J. W. (1995). Agendas, alternatives, and public policies. New York, NY: HarperCollins College Publishers, 273.

Klin, A., and Lemish, D. (2008). Mental disorders stigma in the media: review of studies on production, content, and influences. J. Health Commun. 13, 434-449. doi:10.1080/10810730802198813

Klingemann, H.-D., Hofferbert, R. I., and Budge, I. (1994). Parties, policies and democracy. Boulder, CO: Westview, 318.

Knapp, M., and Beecham, J. (1990). Costing mental health services. Psychol. Med. 20 (4), 893-908. doi:10.1017/s003329170003659x

Kriesi, H., Koopmans, R., and Giugni, M. (1995). New social movements in western Europe: a comparative analysis. London, United Kingdom: UCL Press, 338.

Krosnick, J. A. (1990). Government policy and citizen passion: a study of issue publics in contemporary America. Polit. Behav. 12, 59-92. doi:10.1007/ BF00992332

Landwehr, C., and Ojeda, C. (2020). Democracy and depression: a cross-national study of depressive symptoms and nonparticipation. Am. Polit. Sci. Rev. First view, 1-8. doi:10.1017/s0003055420000830

Lax, J. R., and Phillips, J. H. (2012). The democratic deficit in the states. Am. J. Polit. Sci. 56 (1), 148-166. doi:10.1111/j.1540-5907.2011.00537.x

Lecrubier, Y. (2001). The burden of depression and anxiety in general medicine. J. Clin. Psych. 62, 4-9.

Lefkofridi, Z. (2020). "Opinion-policy congruence," in The oxford handbook of political representation in liberal democracies. Editors R. Rohrschneider and J. Thomassen (Oxford, United Kingdom: Oxford University Press), 740.

Link, B., and Hatzenbuehler, M. L. (2016). Stigma as an unrecognized determinant of population health: research and policy implications. J. Health Polit. Policy Law 41 (4), 653-673. doi:10.1215/03616878-3620869

Loewen, P. J., and Rheault, L. (2019). Voters punish politicians with depression. $B r$. J. Polit. Sci. First view, 1-10. doi:10.1017/S0007123419000127 
Mansbridge, J. (2003). Rethinking representation. Am. Polit. Sci. Rev. 97 (4), 515-528. doi:10.1080/10361146.2013.874404

M. Knapp, D. McDaid, E. Mossialos, and T. Graham (Editors) (2007). in Mental health policy and practice across Europe (Maidenhead, England: Open University Press), 483.

McClure, G. M. G. (2000). Changes in suicide in England and wales, 1960-1997. Br. J. Psychiatry 176, 64-67. doi:10.1192/bjp.176.1.64

McCombs, M., and Donald Shaw, L. (1993). The evolution of agenda-setting research: twenty-five years in the marketplace of ideas. J. Commun. 43 (2), 58-67. doi:10.1111/j.1460-2466.1993.tb01262.x

McCombs, M., and Shaw, D. (1972). The agenda-setting function of mass media. Publ. Opin. Q. 36 (2), 176-187. doi:10.1075/asj.1.2.02mcc

McDonald, M. D., Mendes, S. M., and Budge, I. (2004). What are elections for? conferring the median mandate. Br. J. Polit. Sci. 34 (1), 1-26. doi:10.1017/ S0007123403000322

McSween, J. L. (2002). The role of group interest, identity, and stigma in determining mental health policy preferences. J. Health Polit. Policy Law 27, 773-800.

Mehta, N., Kassam, A., Leese, M., and Butler, G. (2009). Public attitudes towards people with mental illness in England and Scotland, 1994-2003. Br. J. Psychiatry 194 (3), 278-284. doi:10.1192/bjp.bp.108.052654

Meyer, D. S. (2004). Protest and political opportunities. Annu. Rev. Sociol. 30, 125-145. doi:10.1146/annurev.soc.30.012703.110545

Miller, W. E., and Stokes, D. E. (1963). Constituency influence in congress. Am. Polit. Sci. Rev. 57, 45-56. doi:10.2307/440413

Evans-Lacko, S., Corker, E., Williams, P., Henderson, C., and Thornicroft, G. (2014). Effect of the time to change anti-stigma campaign on trends in mentalillness-related public stigma among the English population in 2003-13: an analysis of survey data. Lancet Psychiatry 1 (2), 121-128. doi:10.1016/S22150366(14)70243-3

Monroe, A. D. (1998). Public opinion and public policy, 1980-1993. Publ. Opin. Q. 62 (1), 6-28. doi:10.1086/297828

Mortensen, P. B., et al. (2011). Comparing government agendas: executive speeches in The Netherlands, United Kingdom, and Denmark. Comp. Polit. Stud. 44 (8), 973-1000. doi:10.1177/0010414011405162

Moscone, F., and Knapp, M. (2005). Exploring the spatial pattern of mental health expenditure. J. Ment. Health Pol. Econ. 8 (4), 205-217.

Moscone, F., Knapp, M., and Tosetti, E. (2007). Mental health expenditure in England: a spatial panel approach. J. Health Econ. 26 (4), 842-864. doi:10.1016/ j.jhealeco.2006.12.008

Moynihan, P. (2003). The impact of public opinion on public policy: a review and an agenda. Polit. Res. Q. 56, 29-40. doi:10.1177/ 106591290305600103

Neuner, F. G., Soroka, S. N., and Wlezien, C. (2019). Mass media as a source of public responsiveness. Inter. J. Press Polit. 24 (3), 269-292. doi:10.1177/ 1940161219832416

Ojeda, C. (2015). Depression and political participation. Soc. Sci. Q. 96 (5), 1226-1243. doi:10.1111/ssqu.12173

Ojeda, C., Bernardi, L., and Claudia Landwehr, N. D. (N.d.). Depressive symptoms and the gender gap in political interest. Psychol. Bull. 143 (8), 783-822. doi:10. 1037/bul0000102

Ojeda, C., and Christine, M. (2019). Intersectionality, depression, and voter turnout. J. Health Polit. Pol. Law 44 (3), 479-504. doi:10.1215/ 03616878-7367036

Ojeda, C., and Pacheco, J. (2019). Health and voting in young adulthood. $B r$. J. Polit. Sci. 49 (3), 1163-1186. doi:10.1016/j.ssmph.2019.100531

Olesen, N. (2012). Spending on mental health services in England fell in 2011-12. BMJ 345 (August), e5404. doi:10.1136/bmj.e5404

O'Connor, R. C., Wetherall, K., Cleare, S., McClelland, H., Melson, A. J., Niedzwiedz, C. L., et al. (2020). Mental health and wellbeing during the COVID-19 pandemic: longitudinal analyses of adults in the United Kingdom COVID-19 mental health and wellbeing study. $\mathrm{Br}$. J. Psychiatr. 21, 1-17. doi:10.1192/bjp.2020.212

Pacheco, J., and Ojeda, C. (2019). A healthy democracy? Evidence of unequal representation across health status. OnlineView Polit. Behav. 43, 1245-1267. doi:10.1007/s11109-019-09541-0

Pacheco, J. (2013). The thermostatic model of responsiveness in the American states. State Polit. Pol. Q. 13 (3), 306-332. doi:10.1177/ 1532440013487388
Page, B. I. (2002). "The semi-sovereign public-44 in navigating public opinion: polls, policy, and the future of American democracy," in Jeff manza, fay lomax cook, and benjamin I. Page. New York, NY: Oxford University Press, 325.

Page, B. I., and Shapiro, R. Y. (1983). Effects of public opinion on policy. Am. Polit. Sci. Rev. 77, 175-190. doi:10.2307/1956018

Page, B. I., and Shapiro, R. Y. (1992). The rational public: fifty years of trends in American policy preferences the rational public: fifty years of trends in American policy preferences. Chicago, United States: University of Chicago Press, 506.

P. K. Hatemi and R. McDermott (Editors) (2011). in Man is by nature a political animal: evolution, biology, and politics (Chicago, United States: University of Chicago Press), 352.

Peters, Y., and Ensink, S. J. (2015). Differential responsiveness in Europe: the effects of preference difference and electoral participation. W. Eur. Polit. 38 (3), 577-600. doi:10.1080/01402382.2014.973260

Petrocik, J. R. (1996). Issue ownership in presidential elections, with a 1980 case study. Am. J. Polit. Sci. 40 (3), 825-850. doi:10.2307/2111797

Pitkin, H. F. (1967). The concept of representation. Berkeley and Los Angeles, California: University of California Press, 232.

Rasmussen, A., Kai Mäder, L., and Reher, S. (2018). With a little help from the people? The role of public opinion in advocacy success. Comp. Polit. Stud. 51 (2), 139-164. doi:10.1177/0010414017695334

Rasmussen, A., and Reher, S. (2019). Civil society engagement and policy representation in Europe. Comp. Polit. Stud. 52 (11), 1648-1676. doi:10. $1177 / 0010414019830724$

Reher, S. (2015). Explaining cross-national variation in the relationship between priority congruence and satisfaction with democracy. Eur. J. Polit. Res. 54 (1), 160-181. doi:10.1111/1475-6765.12077

Reher, S. (2018). Gender and opinion-policy congruence in Europe. European Political Science Review 10 (4), 613-635. doi:10.1017/ S1755773918000140

Rehfeld, A. (2009). Representation rethought: on trustees, delegates, and gyroscopes in the study of political representation and democracy. Am. Polit. Sci. Rev. 103 (2), 214-230. doi:10.1017/S0003055409090261

Ross, A. M., Morgan, A. J., Jorm, A. F., and Reavley, N. J. (2019). A systematic review of the impact of media reports of severe mental illness on stigma and discrimination, and interventions that aim to mitigate any adverse impact. Soc. Psychiatr. Psychiatr. Epidemiol. 54, 11-31. doi:10.1007/ s00127-018-1608-9

Rosset, J., Giger, N., and Bernauer, J. (2013). More money, fewer problems? Crosslevel effects of economic deprivation on political representation. W. Eur. Polit. 36 (4), 817-835. doi:10.1080/01402382.2013.783353

Saward, M. (2006). The representative claim. Contemp. Polit. Theor. 5 (3), 297-318. doi:10.1057/palgrave.cpt.9300234

Saxena, S., Graham, T., Knapp, M., and Whiteford, H. (2007). Resources for mental health: scarcity, inequity, and inefficiency. Lancet 370, 878-889. doi:10.1016/ S0140-6736(07)61239-2

Schomerus, G. (2015). Collective levels of stigma and national suicide rates in 25 European countries. Epidemiol. Psychiatr. Sci. 24 (2), 166-171. doi:10.1017/ S2045796014000109

Schumaker, P. D. (1975). Policy responsiveness to protest-group demands. J. Polit. 37 (2), 488-521. doi:10.1017/S0022381600041256

Soroka, S. N. (2002). Agenda-setting dynamics in Canada. Vancouver: University of British Columbia Press, 156.

Soroka, S. N. (2014). Negativity in democratic politics: causes and consequences. New York, NY: Cambridge University Press, 180.

Soroka, S. N., and Wlezien., C. (2010). Degrees of democracy: politics, public opinion, and policy. New York, NY: Cambridge University Press, 241.

Soroka, S. N., and Wlezien, C. (2008). On the limits to inequality in representation. PS Political Sci. Polit. 41 (2), 319-327. doi:10.1017/ S1049096508080505

Stecker, C., and Tausendpfund, M. (2016). Multidimensional government-citizen congruence and satisfaction with democracy. Eur. J. Polit. Res. 55 (3), 492-511. doi:10.1111/1475-6765.12147

Steinhausen, C. (1995). The public as thermostat: dynamics of preferences for spending. Am. J. Polit. Sci. 39, 981-1000. doi:10.2307/2111666

Stimson, J. A., Mackuen, M. B., and Erikson, R. S. (1995). Dynamic representation. Am. Polit. Sci. Rev. 89 (3), 543-565. doi:10.2307/2082973 
Stimson, J. A. (1991). Public opinion in America: moods, cycles, and swings. Boulder, Colo.: Westview, 192.

Stimson, J. A. (2004). “Tides of consent," in How public opinion shapes American politics New York, NY: Cambridge University Press, 173.

Stokes, D. E. (1963). Spatial models of party competition. Am. Polit. Sci. Rev. 57 (2), 368-377. doi:10.2307/1952828

Stout, P. A., Villegas, J., and Jennings, N. A. (2004). Images of mental illness in the media: identifying gaps in the research. Schizophr. Bull. 30 (3), 543-561. doi:10. 1093/oxfordjournals.schbul.a007099

Strøm, K. (1990). A behavioral theory of competitive political parties. Am. J. Polit. Sci. 34 (2), 565-598. doi:10.2307/2111461

Sund, R., Lahtinen, H., Hanna, W., and Mattila, M. (2017b). "How depression suppresses turnout? Findings from population-based register data," in Paper prepared for presentation at the ECPR Joint Sessions of Workshops, Nottingham, United Kingdom, April 25-30, 2017, 25.

Taquet, M., Luciano, S., Geddes, J. R., and Harrison, P. J. (2020). Bidirectional associations between COVID-19 and psychiatric disorder: retrospective cohort studies of 62354 COVID-19 cases in the United States. Lancet Psychiatry 9, S2215-0366(20)30462-4. doi:10.1016/S2215-0366(20)30462-4

Thornicroft, A. (2013). Newspaper coverage of mental illness in England 2008-2011. Br. J. Psychiatry Suppl. 55 (Suppl. 55), s64-s69. doi:10.1192/bjp.bp.112.112920

Thornicroft, G., Rose, D., Kassam, A., and Sartorius, N. (2007). Stigma: ignorance, prejudice or discrimination?. Br. J. Psychiatry 190, 192-193. doi:10.1192/bjp.bp. 106.025791

Thornicroft, G., and Tansella, M. (2004). Components of a modern mental health service: a pragmatic balance of community and hospital care: overview of systematic evidence. Br. J. Psychiatry 185 (OCT), 283-290. doi:10.1192/bjp.185.4.283

TNS, BMRB (2015). Attitudes to mental illness 2014 research report. Available at: https://www.time-to-change.org.uk/sites/default/files/Attitudes_to_mental_ illness_2014_report_final_0.pdf (Accessed April 01, 2015).

UN News (2020). UN leads call to protect most vulnerable from mental health crisis during and after COVID-19. https://news.un.org/en/story/2020/05/ 1063882 (Accessed May 14 2020).

V. Yzerbyt, C. M. Judd, and O. Corneille (Editors) (2004). The psychology of group perception: Perceived variability, entitativity, and essentialism. Psychology Press.
Vliegenthart, R., Walgrave, S., Wouters, R., Hutter, S., Jennings, W., Gava, R., et al (2016). The media as a dual mediator of the political agenda-setting effect of protest. A longitudinal study in six Western European Countries. Soc. Forces 95 (2), 837-859. doi:10.1093/sf/sow075

Walgrave, S., and Van Aelst, P. (2006). The contingency of the mass media's political agenda setting power: toward a preliminary theory. J. Commun. 56 (1), 88-109. doi:10.1111/j.1460-2466.2006.00005.x

Walgrave, S., and Vliegenthart, R. (2012). The complex agenda-setting power of protest: demonstrations, media, parliament, government, and legislation in Belgium, 1993-2000. Mobilization 17 (2), 129-156. doi:10.17813/maiq.17.2. pw053m281356572h

Wittchen, H. U. (2011). The size and burden of mental disorders and other disorders of the brain in Europe 2010. Eur. Neuropsychopharmacol. 21 (9), 655-679. doi:10.1016/j.euroneuro.2011.07.018

Wlezien, C. (2020). "Dynamic representation," in The oxford handbook of political representation in liberal democracies. Editors R. Rohrschneider and J. Thomassen (Oxford, United Kingdom: Oxford University Press), 704.

Wlezien, C., and Soroka, S. N. (2016). "Public opinion and public policy," in Oxford Research Encyclopedia of Politics New York, NY: Springer, 63-75.

Wooldridge, J. M. (2002). Econometric analysis of cross section and panel data. Cambridge, United Kingdom: MIT Press, 752.

Wykes, T., Haro, J. M., Belli, S. R., Obradors-Tarragó, C., Arango, C., and AyusoMateos, J. L. (2015). Mental health research priorities for Europe. Lancet Psychiatry 2, 1036-1042. doi:10.1016/S2215-0366(15)00332-6

Conflict of Interest: The author declares that the research was conducted in the absence of any commercial or financial relationships that could be construed as a potential conflict of interest.

Copyright (c) 2021 Bernardi. This is an open-access article distributed under the terms of the Creative Commons Attribution License (CC BY). The use, distribution or reproduction in other forums is permitted, provided the original author(s) and the copyright owner(s) are credited and that the original publication in this journal is cited, in accordance with accepted academic practice. No use, distribution or reproduction is permitted which does not comply with these terms. 